if adopted, would introduce quite as serious, perbaps a more serious ambiguity. Gravity is an acceleration. When we say that gravity is less in a balloon, or in a mine, than at the surface of the earth, or greater at Glasgow than at Manchester, we are speaking of alterations of $g$-the acceleration due to the earth's attraction; and it would create confusion to employ this word to designate forces also."

Now I do not think that the use of the word gravity as an acceleration is at all common. On the contrary, I have looked into all the books at my command and I cannot find any sup. port whatever for such a use of the word. Every one is accustomed to speak of the "force of gravity." To speak of the force of an acceleration would be a complete anomaly.

All the dictionaries that $I$ have seen support my view that gravity means force, and does not mean acceleration. Take, for example, a good modern book, the Imperial Dictionary. There I find-Gravity (Lat. gravitas from gravis, heavy). I. Weight, heaviness. 2. In philosophy-that force by which bodies tend or are pressed, or drawn towards the centre of the earth-and so on; showing that gravity always means force, though it has various shades of meaning in its occasional applications.

Chamber' Encyclopedia says that the force which causes bodies to fall towards the earth is termed gravity. The article goes on to speak of the force of gravity at the earth, at various heights above the earth, and at the moon. Acceleration is nowhere mentioned as a meaning of the word gravity.

Even if it could be shown that a few people have so far departed from the original etymological sense and prevailing use of the word gravity, as to employ it for an acceleration instead of for a force, this would only prove that the word is, to that limited extent, subject to ambiguity at present. The course that I advocated was to avoid ambiguity by employing the word gravity, used in its most common, and most authoritative sense, instead of a thoronghly ambiguous word weight, in certain cases where misapprehe:asion from the use of the latter word is likely to occur.

It seems to me that Mr. Stoney and Mr. Walker have been led away by thinking of the letter $g$, rather than of the important question at issus. The letter $g$ stands for a number. One way of specifying what number $g$ stands for, is to say that it is the numerical exprission for the acceleration due to gravity, that is, the acceleration due to the force of gravity acting on a falling mass. But this is simply because $g$ is the number which represents the force in Gaussian units on unit mass, and because the force of attraction on any body is proportional to the mass of the body. The latter is an experimenlaily discovered law. To say with Mr. Walker that " the symbol " $g$ ' is gravity," and with Mr. Stoney that "gravity is an acceleration," seem to me expressions ecpually elliptic on the one hand, and, without full explanation, misleading on the other.

If Mr. Stoney offers any method of getting rid of the ambiguity better than that already introduced, others will gladly adopt it. As to Mr. Walker's proposal to confine the use of the word "weight" to mean force, my former letter was partly for the purpose of showing this to be impossible. The act of parlia. ment, regulating weights and measures, settles that matter. Mr. Stoney's letter forms, also, a sufficient answer to Mr. Walker's proposal.

University, Glasgow, March 27

J. T. BotTomley

P.S.-Allow me to thank Mr. Barrett for his information as to the earliest use of spring balances for kilodynes.

If $\mathrm{Mr}$. Walker is serious in proposing to use vires for British kinetic units of force, he ought to avoid centivires and millivires for 100 vires and $\mathrm{I}, 000$ vires respectively. These would be utterly incompatible with the use of the prefixes centi, hekto and milli, filo in the now established metrical system.

\section{Birds as Astronomical Objects}

TuE following note which appears in the last number of Stray Feathers (iii. p. 419), seems to deserve more attention from astronomers than it will perhaps receive unless published where it will meet the eyes of others than Indian ornithologists. I beg leave, therefore, to ask that it may be reproduced in NATURE.

"Looking at the sun this morning, $x$ saw birds very frequently pass the disc. Some were in focus with the sun itself, the wings being quite sharp against the disc, and must have been several miles high, but some were much nearer, and I estimate their distance from me at about two miles by the focus required to see them. These last must, however, have been quite a mile above the earth's surface, and of course many were a great deal higher.

"I suppose they were Kites, but the appearance there was rather as though the wings were long and narrow like those of Swallows, whereas I should have expected the points to be blunted by the irradiation.

"The estimated distance between the tips might be a couple of feet.

"Possibly this may interest some of the readers of Stray Feathers.

"Roorkee, 23rd September, 1875."

On this note the editor of Stray Feathers, Mr. A. O. Hume, remarks :-

"Many of those birds must have been quite invisible to the naked eye. I have no doubt that Vultures, Kites, and Eagles often soar for hours at heights at which they are inus invisible to us, though we and our doings are quite within the grasp of the'r far-seeing gaze. This would help to account for the marvellous manner in which, when an animal is killed in the plains, an apparently speckless sky becomes in an incredibly short space of time crowded with 'an heavenly host.' "'

We know so little with respect to the height at which birds do or can fly, that I am sure all ornithologists would gladly avail themselves of any observations on the part of helioscopists or other astronomers that would bear upon the matter, and I may add that perhaps the evidence they could offer might be of im. portance as regards the migration of birds. In Mr. Hume's remarks I entirely concur.

Magdalene College, Cambridge, March 25

\section{How Typhoid Fever is Spread}

THE case in which the poison of typhoid fever mixed with drinking water was transmitted through nearly a mile of porous earth, and which was mentioned in the abstract of my discourse to the Fellows of the Chemical Society (NATURE, vol. xiii., p. 331), is fully described (in Gernan) in the 6th Report of the Rivers' Commission on the Domestic Water Supply of Great Britain. It will shortly appear, in English, in the Monthly Journal of the Chemical Society. Meanwhile perhaps I may be allowed to trespass upon your space with the following remarks:The outbreak of typhoid fever occurred at the village of Lausen, near Basel, in Switzerland, and it was exhaustively investigated by Dr. A. Hägier of Basel, who has given a full account of it in the "Deutsches Archiv. f. Klin. Med. xi." The source of the poison was traced to an isolated farmhouse on the opposite side of a rintain ridge, where an imported case of typhoid, followed by two others, occurred shortly before the outbreak. A brook which ran past this house received the dejections of the patients and their linen was washed in it. This brook was employed for the irrigation of some meadows near the farm-house, and the effluent water filtered through the intervening mountain to a spring used in all the houses of Lausen, except six which were supplied with water from private wells. In these six houses no case of fever occurred, but scarcely one of the others escaped. No less than 130 people, or seventeen per cent. of the whole population, were attacked, besides fourteen children, who received the infection whilst at home for their holidays, and afterwards sickened on their return to school.

The passage of water from the irrigated meadows to the spring at Lausen was proved by dissolving in it, at the meadows, I8 cwt. of common salt, and then observing the rapid increase of chlorine in the spring water ; but the most important and interesting experiment consisted in mixing uniformly with the water $50 \mathrm{cwt}$. of flour, not a trace of which maise its way to the spring, thus showing that the water was filtere $i$ through the intervening earth and did not pass by an underground channel.

These are the main features of the case, but there are other interesting details showing how carefully the investigation was conducted f for these, however, I must refer Mr. Mitchell Wilson to the works above cited. It: affords a clear warning of the risk which attends the use, for dietetic purposes, of water to which even so-called purified sewage gains access; n jtwithstanding that, as at Lausen, such water may have been used with impunity for years, until the moment when the sewage became infected with typhoid poison.

E. FRANKLAND 